\title{
Could I do something like that?' Recruiting and training foster carers for teenagers 'at risk' of or experiencing child sexual exploitation
}

\begin{abstract}
Child sexual exploitation (CSE) is a category of child abuse that was historically created to recognise the victimhood of children and young people, illuminating the ways that their evolving capacity to consent to sex is manipulated and undermined. Using evidence from the evaluation of specialist foster care provision and a CSE training course for foster carers, this paper considers how training might be used to widen the pool of potential foster carers for children affected by CSE, and identifies qualities displayed by effective carers. It argues that improving the recruitment of foster carers can create safer home environments for teenagers at risk of or experiencing sexual exploitation and reduce the risk of further harm; and that informed and effective foster care provision is crucial to prevent both the sexual exploitation of looked after teenagers, and placement breakdowns that can ultimately increase risk.
\end{abstract}

\section{Key words}

Teenagers, adolescence, foster care, child sexual exploitation, recruitment, training,

\section{Introduction}

This paper begins by reviewing why and how CSE is a form of abuse that primarily affects teenagers, before considering what this means for teenagers in the care system in particular. We argue that care must mean physical, relational and psychological security (Shuker, 2013a) and explore the need for foster care that upholds these forms of safety. Evidence from different strands of an evaluation of the 'Safe Accommodation Project' are integrated to identify perceived barriers for potential foster carers, the impact of training and awareness raising on carers' knowledge and confidence, and some of the qualities of specialist carers in this field. The questions guiding this work are: why are teenagers at risk of CSE, how should the care system support them, and what lessons can be learned for the recruitment and training of foster carers who can provide safe environments to protect teenagers from abuse?

\section{'Child sexual exploitation (CSE)' - recognising the abuse of teenagers}

The term 'CSE' has been adopted in various policy and practice contexts across the UK as an alternative to what was previously termed 'child' or 'juvenile prostitution'. CSE as a category can apply to younger children, but for this discussion it is important to recognise that the framing and history of CSE make it a category of sexual abuse that is overwhelmingly used to describe and respond to harm caused to teenagers and older children, with the average age of victims when they are first identified being 12-15 (Berelowitz et al., 2012; NPPC, 2017).1 Child sexual exploitation (CSE) is recognised as a form and sub type of Child Sexual Abuse (CSA) in government guidance for England (DfE, 2017), and increasingly in public and professional consciousness. The aspect of CSE that makes it distinct is the dynamic of exchange, with campaigners having established that

1 We refer to 'teenagers' throughout this article, reflecting the theme and title of the journal special issue. In relation to looked after children, this should be interpreted as those between the ages of 13-18. 
apparent 'transactions' are evidence of grooming, control and manipulation. This challenges suggestions that children make 'life style' choices, consenting to sexual activity from informed positions. The current definition of CSE highlights exchange, stating that CSE:

"...occurs where an individual or group takes advantage of an imbalance of power to coerce, manipulate or deceive a child or young person under the age of 18 into sexual activity (a) in exchange for something the victim needs or wants, and/or (b) for the financial advantage or increased status of the perpetrator or facilitator. The victim may have been sexually exploited even if the sexual activity appears consensual. Child sexual exploitation does not always involve physical contact; it can also occur through the use of technology."

(DfE, 2017: 5)

Clearly this definition can apply to very young children, given that those who sexually abuse children often give treats, toys or special treatment to victims as part of a grooming process (Beckett and Walker, 2018). However teenagers' evolving capacity to consent to sexual activity makes them more vulnerable to abuse that is then mis-identified as consensual. In England and Wales, sexual activity with a child under 13 is considered statutory rape, but while additional legislation is designed to further protect children over 13 (Sexual Offences Act 2003 and Serious Crime Act 2015), its use and interpretation are influenced by perceptions of children's choice and agency.

Despite the clear definitions of children's rights as stipulated by the UNCRC (1989), in practice, rights to protection are often dependent on constructions of childhood that position the child as innocent, passive and dependent (Ennew, 1986; Shaw and Butler, 1998; Warrington and Brodie, 2018). As a demographic category, teenagers occupy a creative but often hazardous space, where social constructions of childhood and adulthood collide, creating powerful discourses that affect how they are treated. At its simplest, teenagers at risk of or experiencing sexual exploitation have often been perceived as consenting to that sexual activity. If they are 'coerced, manipulated or deceived' (CSE) rather than 'forced or enticed' (CSA), the abuse has often not been identified or responded to adequately (Coy et al. 2013, Pearce, 2013).

Recent reviews of CSE victims' case files in Rotherham, Derby and Oxford among other places have revealed that teenagers were "stigmatised by social workers and police as 'out of control', 'streetwise' and akin to prostitutes" (Delap, 2015). Despite significant progress in policy and practice, it appears that teenagers often still find themselves framed either as a 'threat', a 'victim', or an 'investment' (Hendrick, 1994). Coleman and Hagel (2007) explore the way that those teenagers who are most 'at risk' are invariably enacting risky behaviors that then pose a risk to others, shifting the gaze from their care and wellbeing over into the need for control and restraint. Pearce (2007) develops this further to look at how teenagers' perceived 'risky sexual behaviors' become the focus following abuse, as opposed to awareness of and responses to the nature and extent of the abuse itself. There is strong evidence that teenagers experiencing abuse and exploitation have frequently been judged and ignored by professionals, even when they have tried to talk about what was happening to them (Brodie, 2016).

Beyond the liminality of being between childhood and adulthood, teenagers' experiences are further shaped by the intersection of other identities: gender, socio-economic status, sexuality, religion, disability, ethnicity and looked after status. Teenagers with learning disabilities can be under protected when it is assumed they are asexual (Franklin et al., 2015). Male teenage victims who go missing can be assumed to be involved in criminal activity and/or their offending behaviour is not seen as linked to CSE (McNaughton Nicholls et al., 2014). Teenage girls have suffered discrimination on the basis of stereotypes about promiscuity (Green, 2005) and South Asian Muslim 
teenage girls are often assumed to be safe because of conservative family attitudes to sexuality (Gohir et al., 2013).

An unintended consequence of the political energy expended in England to address CSE in recent years may be that a wide variety of forms of sexual harm/risk experienced by teenagers become labelled as CSE simply because of the currency the label has within contemporary safeguarding practice. Nevertheless CSE as a category has directed much-needed attention to the possibility that teenagers, who appear to be engaging in consensual sexual activity, have, in fact, been manipulated and coerced into that activity. For looked after teenagers this has been an important development, and we now move to consider the specific issues associated with CSE and the care system.

\section{Looked after teenagers affected by sexual exploitation}

In the United Kingdom, children at risk of harm or neglect may meet the legal threshold for being 'looked after' by the State (Children's Act 2004), and looked after teenagers have often been the focus of concerns around sex and risk - though the particular form of this concern has changed as the profile of different social issues has waxed and waned (Brown and Barrett, 2002). Anxiety about the sexual abuse and exploitation of looked-after children has been heightened in recent years in response to the conviction of nine men in Rochdale for sexual offences against a group of teenage girls, one of whom was in a single-occupancy care home during the abuse. Among various responses from the government was an accelerated report from the Children's Commissioner for England, on the findings of their inquiry into child sexual exploitation by gangs and groups, with a specific focus on the issue of looked after children (OCC, 2012).

There are no prevalence studies of the number of looked after children who have experienced CSE. This reflects a lack of data on CSE prevalence more widely, in part because of the lack of clear boundaries between different kinds of abuse, but also because of the different data requirements, categories and processes of social care, the police and third sector agencies (Kelly and Karsna, 2017). However, there is clear disproportionality in the available evidence. Less than one per cent of the general population of children is looked-after, and yet the percentage of looked-after children in research samples of children known or suspected to be victims of CSE victims across England range from 21 per cent to 35 per cent (Shuker, 2013a). This over-representation is partially explained by a common set of risk factors underlying both entry to care and vulnerability to exploitation (Scott and Skidmore, 2006; Coy, 2009; Pearce et al., 2009). However, research since the 1990s in the UK has also consistently drawn attention to the ways that systems and cultures of care-giving can compound that vulnerability (Shaw and Butler, 1998; Corby et al. 2012).

\section{The need for safe foster care}

It is often reported that there are shortages of foster placements for teenagers in England, with older children who have experienced abuse and neglect and/or have emotional and behavioural problems being particularly vulnerable to placement breakdowns (Baginsky et al., 2017). Government reviews of the care system highlight poor placement planning and commissioning practice as contributing to these issues (NAO, 2014; Ofsted, 2014;). More specifically, programs aiming to recruit specialist foster carers for looked-after teenagers, have also been reported to struggle in this regard, including Multi-dimensional Treatment Foster Care for Adolescents (MTFCA) (Dixon et. al, 2013). Research has long reported a tendency for victims of child sexual exploitation to be put in out-of-borough foster, residential, or secure unit placements for their own protection (Creegan, Scott and Smith, 2005; Harper and Scott, 2005), and with the closure of many residential 
homes, local authorities find it challenging to provide care close to children's birth families (Biehal et al., 2014)

This reflects evidence suggesting that children with more complex needs are often moved through a number of cheaper placements before they are moved to more expensive accommodation (e.g. residential/secure), and that those in more expensive care settings in adolescence are more likely to have multiple previous placements (Shuker, 2013b, ).

Teenagers at risk or victims of CSE will certainly need different kinds of placements, according to their individual needs. However, the 'chaotic behaviour' of teenagers suffering abuse and exploitation has sometimes meant they are placed in residential or secure care because of insufficient appropriately supported foster care placements, rather than because these units are in the best interest of the child (Lillywhite and Skidmore, 2006; OCC, 2012; NAO, 2014). Beyond the general difficulties recruiting foster carers for teenagers, there are likely to be specific challenges where CSE is a known concern. The 'South Yorkshire Empower and Protect Project' involved recruiting and training specialist foster carers and providing intensive support and therapeutic input to sustain placements. The evaluation of this project highlighted the 'huge challenge of recruiting foster carers for very complex adolescents'. (Scott et. al, 2017).

Beneath questions of placement supply, are assumptions about what appropriate and safe placements look like, the needs of those who are fostering teenagers affected by CSE, and the pressures they face. A literature review on safe accommodation in relation to CSE (Brodie et al. 2011) identified the importance of safety, felt security, a warm and loving environment, contact with friends and family and contexts where teenagers can develop a sense of self-identity and selfefficacy. Concurrently, other studies have described inappropriate and unsafe care, in which teenagers have often been unprotected because they have been assumed to be in control, and therefore responsible for their own sexual exploitation (Coy, 2008, 2009; Beckett, 2011). In this respect, research has been more illuminating of residential settings than foster care and has shown how young males can be excused or condoned for aggressive/violent behaviour, young females punished for behaving in 'provocative ways' and not being nurturing or compliant, and gay young men judged within hierarchies of masculinity where their own abuse is minimized as a result (Green 2005).

Standard 4 of the Fostering Services National Minimum Standards expects all foster children to feel safe and be safe, and to be "protected from abuse and other forms of significant harm (e.g. sexual or labour exploitation)" (Department for Education, 2011). However, safety is not a simple concept: it is multi-dimensional and subjectively experienced. In their research on the use of secure accommodation in response to CSE in Scotland, Creegan, Scott and Smith (2005) recommend that children should be accommodated at the lowest level of physical security necessary and the highest level of relational security possible. It is recognised that children who are at risk of or experiencing sexual exploitation may not be aware that they are being abused and so may not see themselves as needing a safe placement. However, the reverse can also be true. At the very moment a child at high risk is finally in a physically safe place (a specialist or out of borough placement), the child themselves can feel relationally 'unsafe', unanchored, isolated and highly anxious about their new 'home'. Chronic instability and multiple placement moves have sometimes been cited by care experienced young people and adults as creating further vulnerability to sexual exploitation, even when those placements are made on the grounds of welfare and safety (Coy, 2008, 2009; Hallett, 2016). Both Coy and Hallett's interviewees described being 'moved around', professionals coming and going from their lives, feeling unwanted, unseen, and not like 'normal' children. 
Shuker (2015) draws on empirical data from the evaluation of the Safe Accommodation Project to describe two of the most significant components of relational safety for victims of CSE as acceptance and care. In contrast, teenagers in her sample with previous negative experiences of foster care had encountered the exact opposite: judgement and indifference. The examples of victim-blaming in Shuker's paper highlight the importance of foster carers being supported to reflect on their attitudes and trained to understand CSE specifically, as well as non-discriminatory practice in general. There is some evidence that the recent public focus on CSE in the UK has led to much greater willingness to explicitly address sexual risk in residential care settings (La Valle and Graham, 2016). It is less clear to what extent foster care more generally is being positively affected by this growing awareness, but it is likely that many carers still find talking about sex with teenagers difficult. In their research with 68 foster carers of teenagers, Farmer et al (2004) found that more than half were concerned about the young person's sexual relationships, but two fifths did not discuss sexual health and sexuality with them.

There is also growing awareness of the need for all agencies responding to the issue of CSE to be trauma-informed, adding another dimension to our understanding of safety. Becoming traumainformed means becoming aware that it is possible for a teenager with post-traumatic stress disorder to be physically safe but hyper-vigilant - experiencing the world as relationally and psychologically unsafe because of previous abusive experiences that continue to destabilise the present moment.

Shuker (2013a) has argued that we should therefore view safety as being multi-dimensional: comprising physical, relational and psychological elements. A focus on physical safety to the neglect of relational and therapeutic needs might create respite but is unlikely to reduce a teenager's vulnerability or support their recovery from exploitation. Instead, 'disruption by distance' - placing a teenager far from the perpetrator(s) can trigger risky and extensive missing episodes if the child then tries to get home. Good quality placements have to create physical protection from abuse, relationships that feel genuinely caring and need to respond to psychological needs as well. Among other factors, it is clear that informed and supported carers who are able to build multidimensional safety are a necessity if we are to respond to the needs of these young people. Therefore the rest of this paper addresses the implications of the evaluation findings for the recruitment and training of foster carers for looked after teenagers affected by CSE.

\section{Evaluation of the Safe Accommodation Project}

The following sections of this paper present data relevant to the recruitment and training of foster carers, from an evaluation of the 'Safe Accommodation Project', which ran ran between 2011-2013, and is publicly available (see Shuker, 2013b) It was a multi-strand pilot project developed and delivered by Barnardo's (a large UK-based children's charity), and funded by the Department for Education, that included the recruitment, training and support of specialist carers for children affected by CSE and/or trafficking. 2 It also included the delivery of a two-day awareness raising training on CSE/trafficking and safe accommodation for foster carers and associated professionals across England. In preparation for the project, a small-scale consultation was also undertaken with nine looked after teenagers at risk or experiencing CSE. (see Shuker, 2012).

2 A specialist project worker from a Barnardo's CSE or Trafficking service offered 1-1 support to the teenager, and advice and support to the foster carer, as part of the placement package. CSE and trafficking are distinct but related issues. Unless otherwise stated I have drawn only on data related to CSE foster care placements in this paper. 


\section{Methods}

The evaluation of the Safe Accommodation Project deployed multiple methods of data collection and covered both the training provided to foster carers and professionals, and the specialist foster placements. Evaluation of the foster placements comprised 87 in-person, one-to-one interviews with all the relevant individuals involved, including project staff, social workers, foster carers and the teenagers themselves - with most individuals being interviewed either two or three times over the course of each placement. Quantitative data on indicators of the teenagers' safety and wellbeing was collected via 224 monitoring logs, which were completed weekly by foster carers. Thirteen specialist foster placements were provided: four to victims of trafficking and nine to teenagers affected by CSE. Twelve of the teenagers were female, one was male and four of the 13 placements were pre-existing Barnardo's placements that transferred into the scheme. The published evaluation found that nine of the placements were successful at creating safety and stability and had a range of other positive outcomes.

In addition, 44 awareness-raising courses were delivered by Barnardo's as part of the Safe Accommodation Project and were evaluated in partnership with Barnardo's Training and Consultancy team. A total of 352 foster carers and 311 other professionals attended the course and pre and post-training evaluation forms were completed by $95 \%$ of attendees $(n=630)$, measuring participants' self-reported confidence in their CSE and trafficking related knowledge on a predefined scale. Where additional text answers were provided, this data was coded thematically and frequency counts made of each themes. Interview data was coded thematically using NVivo software, according to a pre-designed framework that was expanded and refined during analysis. Of the 630 participants, $40 \%(n=265)$ consented to being contacted by email for a follow-up online survey by ticking a box on the evaluation form, and $12 \%(n=80)$ completed the survey six months after they were trained.

This paper presents quantitative and qualitative data from the pre and post-training evaluation surveys of 352 foster carers, the 37 carers who completed the follow up online survey, and some additional interview data from the 13 specialist foster carers as well. This data is not generalisable, and while it raises important issues in relation to the role of training and awareness-raising, the small sample size does limit its wider applicability. The evaluation was approved by the University of Bedfordshire and Barnardo's research ethics committees and all the names in this paper are pseudonyms. For full details of the methodology and approach to analysis see Shuker (2013b).

\section{Results: recruiting foster carers for teenagers at risk or victims of CSE}

In this section of the paper we draw on the data described above to identify barriers that might prevent carers being willing to foster teenagers where CSE is a concern, and suggest that targeting, and providing training to, existing carers should be integrated into future recruitment strategies. We then reflect on what the evaluation revealed about the qualities, experience and availability of potential carers.

\section{Barriers to providing specialist foster care to sexually exploited teenagers}

The Safe Accommodation Project struggled to recruit new people to the role of specialist foster carer, and survey data gathered as part of the training evaluation highlights some of the potential reasons for this. 
In the first year of the project, Barnardo's regional offices incorporated messages about the need for specialist foster carers into existing recruitment strategies (adverts, enquiry packs and information events for example). Feedback highlighted that the content of the role of specialist foster carer was challenging, especially for those with no experience of supporting teenagers with complex needs. In the second year of the project efforts therefore focussed on a national media campaign that was targeted specifically at recruiting foster carers from professionals with experience of working with vulnerable young people, or from more general 'helping professions'.3 Despite successfully targeting these groups, the campaign ultimately yielded fewer carers than came from attempts to convert existing Barnardo's carers to the role of specialist carer. Of the 6,121 'hits' on the Barnardo's recruitment website, only 422 converted to enquiries, and only one couple went on to provide a placement over the two years of the evaluation.

The campaign was intentionally transparent about the potential challenges of becoming a specialist CSE/trafficking carer, but the Barnardo's fostering team reported that many enquiries ended when people learned about what the role might involve day to day. Data from the training element of the evaluation can potentially help to put this into perspective. Foster carers completing the online survey six months after attending one of the awareness raising courses on CSE and trafficking were asked 'Would anything make you hesitant to consider caring for a young person at risk, or a victim, of sexual exploitation or trafficking?'

Of the 37 foster carers who responded to this open-text question, 17 said 'No' there was nothing that would prevent them from taking on this role. However a further 17 wrote that potential risks to themselves, their children, or other children in their care would make them hesitant. One carer provided the following comment, when invited to expand their answer: "I still have my own teenage boys living at home so it's not something I would consider at the moment because of all the safeguarding issues", while another highlighted "the effect on any other foster kids or my own family" (online follow-up survey).

Other barriers reported by foster carers in answer to this question (in order of frequency reported) were:

- a lack of confidence that they would be well-supported;

- the challenges of being a single carer, and

- a lack of knowledge about how best to provide care.

Analysis of pre-training evaluation forms revealed that only 22 per cent of carers reported being confident or very confident in their understanding of how children and young people become sexually exploited/trafficked and the support they need. If existing foster carers lacked confidence and awareness, it is perhaps unsurprising to find so few non-carers coming forward to become CSE specialists through regional and national marketing.

\section{The impact of training on willingness to consider specialist foster care}

In response to these challenges, the pre and post-training evaluation data suggests that awareness raising can be used as a recruitment tool to improve people's confidence to care for a teenager affected by CSE. More than go per cent of the 630 participants on the course reported feeling either 'confident' or 'very confident' in their knowledge and understanding of CSE/trafficking after two days training. 4 The number of foster carers who reported feeling 'quite' or 'very confident' to

3 E.g. education professionals, social workers, health care professionals, care workers, probation services. 4 Across all five areas of CSE knowledge enquired about, the average percentage of those who felt confident or very confident in their understanding was only $27 \%$ pre-training, rising to an average of $95 \%$ post training. 
support a sexually exploited teenager increased from 31 per cent pre-training to 83 per cent posttraining. Training participants were asked to explain their reported confidence levels (to support a trafficked or sexually exploited teenager) before and after training, and where multiple reasons were given these were coded and counted separately. Ninety-four per cent of the explanations provided for low confidence by foster carers before the course centred on a lack of training or previous experience.

"I don't know enough about the subjects and I haven't any experience with anybody who has been through these experiences. (Foster carer - pre-course evaluation form)

After the course, 82 per cent of the explanations provided by foster carers who said they were now 'quite' or 'very confident' attributed this to knowledge gained from the course.

"Feeling empowered since enrolling on this course. Feel I can identify the vulnerabilities and risks for the child/young person." (Foster carer-post-course evaluation form)

The 17 per cent of foster carers who reported feeling either 'not at all' or 'only slightly' confident to support a sexually exploited teenager after the training described a need for more experience (35 per cent of coded responses); a need for further training (31 per cent of responses); circumstantial barriers, including a lack of professional support (24 per cent of responses); and a sense that they lacked the right skills or just didn't want to do this kind of role (10 per cent of responses).

"I feel I have learned a great deal but equally I feel that these areas in particular require experience in order to be confident in helping children and young people who have been through either ordeal." (Foster carer - post-course evaluation form)

"As I have never been involved in these sorts of cases I do not feel 'very confident' but this training has given me the confidence not to refuse these cases." (Foster carer-post-course evaluation form))

The online survey, emailed to course participants six months after training, was explicit about the potential impact of the course, asking carers to what extent they agreed with the statement "Going on the training made me more likely to consider fostering a young person who has been sexually exploited or trafficked". Of the 37 who responded, 18 either 'agreed' or 'strongly agreed', citing their increased knowledge and confidence alongside a greater desire to support this vulnerable group. The 14 respondents who were 'not sure' and the five who either 'disagreed' or 'strongly disagreed' were worried about the potential impact on/risk to children in their care or said they would need more support and training to take on this type of placement.

As described earlier, the number of foster carers who reported feeling 'quite' or 'very confident' to support a sexually exploited teenager increased from 31 per cent pre-training to 83 per cent immediately after the training. The data from the online follow-up survey suggests that a much smaller number would report, after six months, that the training had actually made it more likely they would consider fostering a young person who had been sexually exploited or trafficked. There

These areas were: CSE/trafficking as a child protection issue; how children and young people become sexually exploited/trafficked and the support they need; how children and young people are affected by CSE/trafficking and the behaviours they may present; the specific risks which may present for children and young people who are sexually exploited/trafficked whilst in safe accommodation; and the need for multi-agency working and the additional support needs of young people and carers. Survey response options were 'Not at all confident', 'Slightly confident', 'Quite confident' and 'Very confident'. 
are clear limitations to the online survey, not least that those who were engaged enough to complete it may not be representative of the wider pool of carers.

Nevertheless, it suggests that there is a role for training and awareness raising in reducing some of the potential barriers to foster carers considering a placement where CSE is known or suspected especially where these barriers relate to knowledge. However, the greater ambivalence around supporting a young person reported six months later also suggests that agencies and local authorities should follow up potential carers relatively quickly after they complete a training course, to capitalise on the short-term impact of this new knowledge and confidence. There are also likely to be some existing carers who are capable of this kind of fostering but lack confidence, and who would need to be supported to recognise the experience they already have. For example, one of the Barnardo's carers whose placement had converted to specialist status in Year 1 of the project explained that it was only when she realised she was already caring for a young woman at risk of sexual exploitation that she changed her mind about becoming involved.

"It was just a bit scary at first - could I do something like that? Do you know what I mean? I was thinking the worst. I was thinking of a child who would be hard to manage, would be out all hours - sounds like Rhiannon! Who would be quite cheeky, stealing - Rhiannon doesn't steal - not trustworthy, answering back, drinking, smoking. But Rhiannon's not scary. Overall, it's not the image I first had." (Interview with Barnardo's Specialist Foster Carer)

Finally, while this data suggests that training and awareness raising courses may increase the pool of potential specialist carers, interviewees within the specialist placement strand of the evaluation agreed that not all carers could offer the kind of support these teenagers need. Twenty one-to-one interviews were conducted with the 13 specialist foster carers over the two years of the evaluation, each lasting between 45 -90 minutes, as well as 77 further interviews with relevant stakeholders (including young people). Analysis of these interviews highlighted particular qualities carers needed if they were to manage the potential challenges of these placements.

\section{Targeting existing carers with the necessary skills and experience}

While the national advertising campaign Barnardo's ran only yielded one new foster carer, 19 existing Barnardo's foster carers were approved as specialist and successfully transferred over to the scheme during the life of the project, of whom 11 went on to have a placement. Barnardo's experience suggests that recruitment for specialist CSE roles could fruitfully focus on existing foster carers with the skills and experience of looking after young people with complex needs rather than attracting new carers from relevant professions. This reflects the experience of the South Yorkshire Empower and Protect Project (see Scott et al., 2017 for the project evaluation) where the challenge of recruiting specialist CSE foster carers was significant, and where supervising social workers ultimately approached existing carers who they judged capable of managing the complexity of those referred.

Within the Safe Accommodation Project, 11 of the 13 carers had experience fostering, raising, or working with teenagers when they took on a specialist placement. However, carer inexperience did not necessarily dictate the outcomes of the other two placements, one of which broke down after days, while the other achieved extremely good outcomes. Neither was it necessary to have worked professionally with vulnerable young people to achieve positive outcomes, since only three of the 13 carers had previously had such a role. 
Analysis of interviews suggested that carers within stable and positive placements had in common four qualities:

1. An ability to cope with challenges

2. Confidence in holding their boundaries

3. Commitment to the task and

4. Compassion towards the teenagers in their care.

These qualities resonate with an authoritative parenting style, where caregivers are able to combine warmth and boundaries (Baumrind, 1966), and which is associated with a range of positive outcomes for teenagers (Steinberg, 2001). In stable placements where teenagers and foster carers had developed warm, trusting relationships, carers were balancing the need to attend to safeguarding measures (the achievement of physical safety), and demonstrations of care and positive attention (the achievement of relational safety). Over time, the acceptance, warmth and practical support offered by foster carers helped teenagers interpret unpopular rules, boundaries and safety measures as expressions of care, even where these were initially resisted.

"Javad and Molly want to know my friends. And that was the main rule - I just thought 'That's embarrassing!' So at first I used to hate it. Oh my God. But now it's good, like. If my battery runs out they'll call one of my friends, and my friends come round here." (Interview with Mohammed, young man in specialist foster placement).

"I was going to lose complete control if I gave in to anything and I just stuck to my rules and I didn't change. So I think she was just testing me there but she's fine now, when she's done something wrong I ground her and she's okay." (Interview with Shauna's specialist foster carer).

Specialist carers implemented a variety of safety measures including curfews, chaperoning and regulating internet access. The teenagers in their care generally did not see the need for these, particularly at the start of placements. Nevertheless, carers often managed to avoid the conflict and escalation that might have otherwise triggered placement breakdown. Supervising and local authority social workers attributed this to resilience on the part of these carers, and their capacity to express care and concern, even in trying situations.

"The foster carers are really good with Shauna, they support her really well...A lot of foster carers might get a bit worn down by it, the fact that Shauna isn't changing, she's still carrying on with the same behaviours. But Sally and James are very good at just going, 'Okay, let's move on'." (Interview with local authority social worker).

"The child will come in - it might be two in the morning, it might be nine in the morning - but the carers are there saying, 'Are you alright? Do you need to get a shower? Do you need something to eat? In a different placement, you might get carers freaking out about what time they come back." (Interview with Barnardo's fostering social worker).

This data suggests that future specialist foster care recruitment needs to target carers with the confidence and ability to implement safeguarding measures in a non-judgemental and compassionate manner. Although it may not always be necessary, experience caring for teenagers is likely to underpin such confidence. Thirty-one per cent of the 352 foster carers attending the training reported before the course that they were 'very' or 'quite confident' to support a sexually exploited child. When asked to give the reason for their reported level of confidence, $85 \%$ of their 
answers centred on their previous experience of fostering or providing emotional support/a safe environment to vulnerable teenagers, illustrated by this comment from one foster carer: "Many years of experience with young people involved with CSE but not in trafficking, however, training course has helped fill in the gaps." (pre-course evaluation form).

Finally, in establishing placements for teenagers at risk of or experiencing sexual exploitation, there is a need to assure that foster carers are sufficiently available (preferably full-time) in the early days of a placement, when education provision is still being scoped and there is increased risk of a teenager going missing. The foster carers interviewed explained that the role was 'intensive' and required energy and availability. Many 'front-loaded' the placement with interesting activities early on, and at times when they suspected that boredom might trigger missing episodes.

"The female carer would take Jessica out to get her nails done, or to go to Zumba, anything she wanted to do to try and engage her, they would do. They tried to find activities for Jessica at times when she typically went missing from home in the hope that this would act as a deterrent." (Interview with Barnardo's fostering social worker).

\section{Discussion and implications}

The evaluation of the Safe Accommodation Project emphasized that safe foster placements should offer more than physical protection from sexually exploitative contexts and people. They also need to create warm and trusting relationships and respond to teenagers' psychological needs. While public and professional awareness of CSE has undoubtedly increased, it is less clear that the quality and quantity of suitable foster placements for children at risk or experiencing CSE has improved. Given the heightened vulnerability of looked after children, it is vital that foster carers are supported and equipped to care for teenagers. This is a crucial aspect of early intervention, potentially preventing the placement breakdown and instability that often precedes placements into residential or secure settings. $5 \mathrm{It}$ is highly likely that specialist placements for victims of CSE are not equally available to children and young people across the breadth of the United Kingdom. Future research could therefore establish what numbers of placements may be needed and in which parts of the country - in order to inform more coherent planning. Given the barriers to fostering a child affected by sexual exploitation reported by potential carers in the evaluation, policy makers should also consider how to incentivise greater investment in this kind of care by local authorities and independent fostering agencies.

The data presented suggest that recruitment drives to find carers for the task of fostering teenagers where CSE is a concern could make use of training and awareness raising courses. These have the potential to significantly improve carers' short-term confidence in relation to the role. Fostering agencies could also consider how to create a pathway to further learning, respite care or specialist placements, in order to capitalise on this confidence and to prevent it dissipating over time.

Recruitment and training activity should draw on the concept of multiple layers of 'safety' and note the barriers reported here, including the risks to other children in the home, concerns about the level of support available and low confidence resulting from a lack of knowledge and experience. Existing carers should be targeted, with experience of supporting teenagers, and/or the capacity to confidently safeguard and act protectively whilst creating a warm and caring environment in the home. It may well be that some carers with these qualities will still need encouragement to

5 Services that support parents and families affected by CSE are equally, if not more important in this regard, with recent evaluations highlighting their potential to prevent entry into care (Scott and McNeish, 2017) 
recognise their own skills and abilities, in the face of what can seem like a particularly daunting fostering task.

\section{References}

Baginsky, M., Gorin, S., and Sands, C. (2017) The fostering system in England: Evidence review. Research report: Executive summary. King's College London and Quest Research and Evaluation Ltd.

Baumrind, D. (1966), "Effects of authoritative parental control on child behavior", Child Development, Vol. 37 No. 4, pp. 887-907.

Beckett, H. (2011) Not a World Away: The Sexual Exploitation of Children and Young People in Northern Ireland. Ilford, Barnardo's.

Beckett, H. and Walker, J. (2018) [Words matter: Reconceptualising the conceptualisation of child sexual exploitation' in Beckett, H. and Pearce, J. (eds) Understanding and Responding to Child Sexual Exploitation Oxon: Routledge.

Berelowitz, S., Firmin, C., Edwards, G., Gulyurtlu, S. (2012) "I thought I was the only one. The only one in the world" The Office of the Children's Commissioner's Inquiry into Child Sexual Exploitation In Gangs and Groups. London. OCC.

Biehal, N., Cusworth, L., Wade, Jim., Clarke, S. (2014) Keeping children safe : allegations concerning the abuse or neglect of children in care. Research Report. Impact and Evidence Series . NSPCC

Brodie, I. with Pearce, J., Melrose, M., and Warrington, C. (2011) Providing Safe and Supported Accommodation for Young People who are in the Care System and who are at Risk of, or Experiencing, Sexual Exploitation or Trafficking for Sexual Exploitation. Luton: University of Bedfordshire.

Brodie, I. with D'Arcy, K. Harris, J. Roker, D. Shuker, L. and Pearce, J. (2016) The participation of young people in child sexual exploitation services: A scoping review of the literature. Luton, University of Bedfordshire.

Brown A. and Barrett D. (2002) Knowledge of Evil. Devon, Willan Publishing.

Coleman, J. and Hagell, A. (2007) Adolescence, Risk and Resilience: Against the Odds. London, John Wiley.

Corby, B., Shemmings, D., and Wilkins, D (2012) Child abuse: an evidence base for confident practice. Open University Press.

Coy, M. (2008) 'Young women, local authority care and selling sex: Findings from research', British Journal of Social Work, 38(7), p. 1408-27.

Coy, M. (2009) 'Moved around like bags of rubbish that nobody wants': How multiple placement moves can make young women vulnerable to sexual exploitation', Child Abuse Review, 18, 254-266. 
Coy, M., Kelly, L., Elvines, F., Garner, M., and Kanyeredzri, A (2013) 'Sex without consent, I suppose that is rape': how young people in England understand sexual consent. A report commissioned for the Office of the Children's commissioner for England and London Metropolitan University.

Coy, M (2016) 'Joining the dots on sexual exploitation of children and women: A way forward for UK policy responses'. Critical Social Policy. Vol 36, Issue 4, pp. 572 - 591

Creegan, C., Scott, S. and Smith, R. (2005) The Use of Secure Accommodation and Alternative Provisions for Sexually Exploited Young People in Scotland. Glasgow: Barnardo's Policy and Research Unit.

Delap, L. (2015) 'Child welfare, child protection and sexual abuse, 1918-199o'. History and Policy. Available at http://www.historyandpolicy.org/policy-papers/papers/child-welfare-child-protectionand-sexual-abuse-1918-1990

Department for Education (2011) Fostering services: national minimum standards. Available at: http://publications.education.gov.uk/ search using the ref: DfE-00029-2011

Department for Education (2017) Child sexual exploitation: Definition and a guide for practitioners, local leaders and decision makers working to protect children from child sexual exploitation.

Dixon, J., Biehal, N., Green, J., Sinclair, I., Kay, C and Parry, E. (2013) Trials and Tribulations: Challenges and Prospects for Randomised Controlled Trials of Social Work with Children. British Journal of Social Work. 1-19. doi:10.1093/bjsw/bcto35

Ennew, J. (1986) The Sexual Exploitation of Children. Cambridge. Polity Press

Farmer, E., Moyers, S., and Lipscombe, J. (2004) Fostering Adolescents. London. Jessica Kingsley Publishers Ltd.

Franklin, A., Raws, P., and Smeaton, E. Unprotected, overprotected: Meeting the needs of young people with learning disabilities who experience, or are at risk of, sexual exploitation. Barnardo's. Barkingside, Ilford.

Gohir, S. (2013) Unheard Voices: The Sexual Exploitation of Asian Girls and Young Women. Birmingham: Asian Women's Network.

Green, L. (2005) Theorizing sexuality, sexual abuse and residential children's homes: Adding gender to the equation. British Journal of Social Work. 35(4), 453-481

Hallett, S (2016) 'An Uncomfortable Comfortableness': 'Care', Child Protection and Child Sexual Exploitation'. British Journal of Social Work (2016) 46, 2137-2152

Harper, Z. and Scott, S. (2005) Meeting the needs of sexually exploited young people in London. Ilford. Barnardo's

Hendrick, H. (1994) Child Welfare: England, 1872-1989. London. Routledge

Kelly, L. and Karsna, K. (2017) Measuring the scale and changing nature of child sexual abuse and child sexual exploitation: Scoping report. London: Centre for Expertise on Child Sexual Abuse. 
Sexual Offences Act 2003. [online] Available at:

http://www.legislation.gov.uk/ukpga/2003/42/section/74 [Accessed 21 June 2018].

Serious Crime Act 2015 online] Available at:

http://www.legislation.gov.uk/ukpga/2015/9/contents/enacted [Accessed 21 June 2018].

LaValle. I. and Graham, B. (2016) Child sexual exploitation: support in children's residential Homes. London: Department for Education.

Lillywhite, R. and Skidmore, P. (2006) 'Boys are not sexually exploited? A challenge to practitioners', Child Abuse Review 15, 5, 351-361.

McNaughton Nicholls, C., Cockbain, E., Brayley, H., Harvey, S., Fox, C., Paskell, C., Ashby, M., Gibson, K., and Jago, N. (2014) Research on the sexual exploitation of boys and young men - A UK scoping study. Summary of findings. Ilford, Barnardo's.

National Audit Office (2014) Children in Care. London: NAO.

OCC (2012) Briefing for the Rt. Hon Michael Gove MP, Secretary of State for Education, on the Emerging Findings of the Office of the Children's Commissioner Inquiry into Child Sexual Exploitation in Gangs and Groups with a Special Focus on Children in Care. Office of the Children's Commissioner, London.

Ofsted (2014) The sexual exploitation of children: it couldn't happen here, could it?

Pearce J. J (2007) "Sex, risk and resilience in adolescence" in Coleman, J. and Hagell, A.

Adolescence, risk and resilience: against the odds Chichester: John Wiley

Pearce, J. (2009) Young People and Sexual Exploitation: 'It's not Hidden, You Just Aren't Looking' London: Routledge

Pearce, J,J. (2013) 'Contextualising Consent' in Melrose, M and Pearce, J (eds) (2013) Critical Perspectives on child sexual exploitation and related trafficking Palgrave Macmillan

Scott, S. and Skidmore, P. (2006) Reducing the Risk: Barnardo's Support for Sexually Exploited Young People - A Two-Year Evaluation. Barnardo's, Ilford, Essex.

Scott, S. and McNeish, D. (2017) Supporting parents of sexually exploited young people: An evidence review. London: Centre for expertise on child sexual abuse.

Scott, S., Lloyd, S., Wright, C., and Ludvigsen, A. (2017) South Yorkshire Empower and Protect Child Sexual Exploitation Innovation Project Evaluation report. London: Department for Education.

Shaw, I. and Butler, I. (1998) 'Understanding young people and prostitution: a foundation for practice?' British Journal of Social Work. 28, pp.177-96

Shuker, L. (2012) The Barnardo's Safe Accommodation Project: Consultation with young people. Available at https://www.beds.ac.uk/_data/assets/pdf_file/0006/223845/The-Barnardos-SafeAccommodation-Project-Dr-Lucie-Shuker.pdf

Shuker, L. (2013a), "Constructs of safety for children in care affected by sexual exploitation", in Melrose, M. (Ed.) Critical Perspectives on Child Sexual Exploitation and Trafficking, Palgrave Macmillan, London, pp. 125-38. 
Shuker, L. (2013b), Evaluation of Barnardo's Safe Accommodation Project, University of Bedfordshire, Luton.

Shuker, L. (2015). Safe foster care for victims of child sexual exploitation, Safer Communities, 14 (1), $37-46$.

Steinberg, L. (2001) We know some things: parent-adolescent relationships in retrospect and prospect. Journal of Research on Adolescence, 11(1), 1-19.

National Police Chiefs Council (2017) Child Sexual Exploitation (CSE) offences across England and Wales (November 2014 to October 2015). Available at http://www.npcc.police.uk/documents/CSEProblemProfile.pdf

UNICEF (1989). United Nations Convention on the Rights of the Child.

Warrington, C. and Brodie, I. (2018) 'Developing participatory practice and culture in CSE services' in Beckett, $\mathrm{H}$. and Pearce, J. Understanding and responding to Child sexual Exploitation' Routledge: 121-134 